\title{
A Rat Model for the Study of Growth Failure in Uremia
}

\author{
Cyril Ghantler, ${ }^{[18]}$ Ellin Lieberman, and Malgolm A. Holliday \\ Department of Pediatrics, University of California, San Francisco, and San Francisco \\ General Hospital, San Francisco, California, USA
}

\begin{abstract}
Extract
The growth of children with chronic renal disease is poor and the cause of this stunting is not known. Various factors have ben implicated and it is difficult to evaluate their relative importance in clinical studies. Accordingly, there is a need for an animal model, preferably one which enables the effect on growth of a number of factors to be studied separately and over a reasonably short period of time. The growth and food intake of male and female rats rendered uremic by $5 / 6$ nephrectomy was observed between 40 and 70 days of age for male rats and between 35 and 70 days of age for female rats. Final mean body weight for males with uremia $(243 \mathrm{~g} \pm 32 \mathrm{~g})$ was significantly less than for control males $(323 \mathrm{~g} \pm 24 \mathrm{~g})$; final mean body weights for female rats were also significantly different $(172 \mathrm{~g} \pm 17 \mathrm{~g} ; 223 \mathrm{~g} \pm 21 \mathrm{~g})$. The differences in body weight were apparent from 50 days onwards. Final tail length was significantly less in female uremic rats compared with their control subjects $(173 \mathrm{~mm} \pm 8 \mathrm{~mm} ; 183 \mathrm{~mm} \pm$ $7 \mathrm{~mm}$ ). Uremic rats matched for body weight with control rats consumed significantly fewer calories; for both groups the average difference was about $15 \%$. Multiple regression analysis of weight gain against age and calorie intake suggests that there may be an increase in the calorie cost of growth in rats with uremia, but these findings require confirmation in paired feeding studies.
\end{abstract}

\section{Speculation}

These studies suggest that this rat model can be used for the investigation of alterations in energy balance, body composition, and metabolic functions in uremia. It should be possible to study the effects of single variables in the pathogenesis of growth retardation by appropriate manipulations halfway through the growth period.

\section{Introduction}

Children with chronically impaired renal function often exhibit poor growth. Although the metabolic consequences of renal failure, such as acidosis, altered vitamin D metabolism, and the susceptibility to infection may alter growth [11], it is frequently found that even when these abnormalities are corrected, growth remains poor. The increasing availability of chronic hemodialysis and renal transplantation has meant that more undergrown children with renal disease are surviving into adult life.

Development of an animal model which satisfactorily represented the poor growth associated with uremia would be valuable in investigating the impact of chronic renal failure on the composition and metabolic functions of the body and their relation to 
growth. This report, which details our experience with a rat model, is particularly concerned with the effect of uremia on food intake and the relation between calorie intake, growth, and uremia.

\section{Materials and Methods}

Male and female Sprague-Dawley rats were obtained at 21 days of age, body weight $40-50 \mathrm{~g}$, from the Charles River Breeding Laboratories, Wilmington, Mass. They were placed in individual hanging cages ( 38 by 22 by $19 \mathrm{~cm}$ ) and maintained at an environmental temperature of $22^{\circ}$, with a light cycle of approximately $10 \mathrm{hr}$.

Between 22 and 24 days of age, experimental animals were partially nephrectomized using the technique described by Platt et al. [9]; $2 / 3$ of the left kidney was removed at the first stage of the procedure and 1 week later the right kidney was excised. Sham operations, where the peritoneum was opened and the kidney exteriorised, were performed in a control group. All animals received intraperitoneal $0.9 \% \mathrm{NaCl}$ solution and intramuscular penicillin after surgery.

After operation all animals were fed ad libitum with a diet which provided $4.4 \mathrm{kcal} / \mathrm{g}$ food. The diet contained $18.5 \%$ dried egg white, $25 \%$ casein, $15 \%$ corn oil, $38 \%$ dextrose, and $3.5 \%$ Jones and Foster salts [7]. Vitamin diet fortification mixture was added to the diet in the amounts recommended by the manufacturer [12]. The final mixture was calculated to contain $34 \%$ of the calories as protein and $0.2 \%$ of sodium by weight.

Rats in both groups were weighed, at weekly intervals, to an accuracy of $\pm 1 \mathrm{~g}$, and tails were measured, also at weekly intervals, to an accuracy of $\pm 1 \mathrm{~mm}$, using the method of De Groot [6]. Dietary intake was determined twice weekly by weighing the amount of feed consumed. The feed packed down well into feeding jars and spillage was minimal; waste trays were inspected regularly and food consumption data was discarded when spillage was noted. Body weight, tail lengths, and calories consumed per day were plotted against age for each rat and values at 5-day intervals were interpolated directly from the graphs; in this way weight gain and calorie intake could be compared at successive 5-day intervals throughout the 30 -day period of observation for each rat.

Blood urea nitrogen (BUN) was measured on an AutoAnalyzer at weekly intervals from blood taken from a cut in the dorsal foot vein.

All experimental animals that maintained a BUN of more than $70 \mathrm{mg} / 100 \mathrm{ml}$ throughout the study and that survived for up to 80 days were accepted.

\section{Results}

Of 75 female uremic rats, 10 fulfilled the criteria for acceptance; data from these rats were compared with 12 controls. The number of uremic rats excluded because of death soon after operation was approximately equal to the number who failed to maintain a BUN greater than $70 \mathrm{mg} / 100 \mathrm{ml}$.

There was no significant difference in the mean BUN between the female and male uremic rats (104 $\mathrm{mg} / 100 \mathrm{ml} \pm 30 \mathrm{mg} / 100 \mathrm{ml}$ and $110 \mathrm{mg} / 100 \mathrm{ml} \pm 28$ $\mathrm{mg} / 100 \mathrm{ml})$ or between the controls $(26 \mathrm{mg} / 100 \mathrm{ml} \pm$ $8 \mathrm{mg} / 100 \mathrm{ml}$ and $25 \mathrm{mg} / 100 \mathrm{ml} \pm 4 \mathrm{mg} / 100 \mathrm{ml}$ ).

Mean body weight of female uremic rats analyzed at intervals of 5 days was significantly less $(P<0.05$ : student $t$ test) than female controls from 40 to 70 days of age, when the study was concluded (Table I). The difference in weights of the male rats was significant at 50 days and, as observed in the females, the difference became greater with time (Figs. 1 and 2).

Tail growth in the uremic rats was less than the controls (Table I); in the female group the difference was significant at 60 days onwards (Figs. 3 and 4). In the males, although the uremic rats had shorter tails, the differences were not significant; however, the mean increase in tail length of the uremic rats between 40 and 70 days was significantly less (uremic: $56 \mathrm{~mm} \pm 8$ $\mathrm{mm}$; control: $65 \mathrm{~mm} \pm 9 \mathrm{~mm} ; t=2.4 ; P<.05$ ).

Uremic rats consumed fewer calories than did control rats. This was not simply an effect of their smaller size, for when the rats were divided into ranges of body weight so that the mean body weight of the uremic and control rats in each group was the same, there was a significant difference in calorie intake in most groups (Table II).

An attempt was made to compare the efficiency of calorie utilization for growth in uremic and control rats by using multiple linear regression analysis [13]. A significant regression of weight gain with age and calorie intake was found for male rats between 40 and 70 days; this was not improved significantly by inclusion of body weight as one of the variables. The regression for female uremic rats was not significant, possibly because of the low calorie intakes in some rats towards the end of the study period when growth had ceased. For the male rats the regression equation was: control weight gain (grams per day) $=-0.114$ age (days) $\pm 0.015+0.057$ calorie intake (kilocalories) \pm 
Table I. Comparison between body weight and tail length of uremic and control rats

\begin{tabular}{|c|c|c|c|c|c|}
\hline \multirow{2}{*}{ Subjects } & \multirow{2}{*}{$\mathrm{n}$} & \multicolumn{2}{|c|}{ Body weight, $\mathrm{g}$ (mean $\pm 1 \mathrm{sD}$ ) } & \multicolumn{2}{|c|}{ Tail length, $\mathrm{mm}($ mean $\pm 1 \mathrm{SD})$} \\
\hline & & Initial & Final & Initial & Final \\
\hline \multicolumn{6}{|c|}{ Male, 40-70 days } \\
\hline Control & 12 & $123 \pm 18$ & $323 \pm 24.1$ & $132 \pm 12$ & $197 \pm 8$ \\
\hline Uremic & 9 & $119 \pm 20$ & $243 \pm 32^{1}$ & $136 \pm 8$ & $192 \pm 11$ \\
\hline \multicolumn{6}{|c|}{ Female, $35-70$ days } \\
\hline Control & 20 & $110 \pm 16$ & $223 \pm 21^{1}$ & $131 \pm 9$ & $183 \pm 7^{1}$ \\
\hline Uremic & 10 & $99 \pm 16$ & $172 \pm 17^{1}$ & $132 \pm 6$ & $173 \pm 8^{1}$ \\
\hline
\end{tabular}

${ }_{1}^{1}$ Differences between means significant at $1 \%$ level (Student $t$ test).

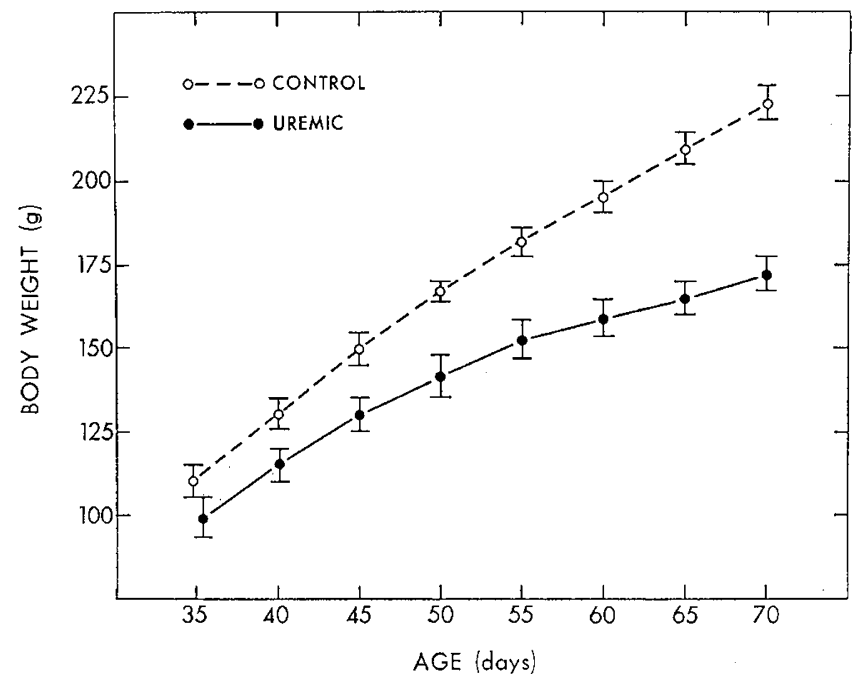

Fig. 1. Female rats: body weight plotted against age, showing the mean and SEM $\times 2$ at 5 -day intervals.

$0.013+8.082$; uremic weight gain (grams per day) $=$ -0.145 age (days) $\pm 0.015+0.095$ calorie intake (kilocalories) $\pm 0.0143+6.231$.

When arbitrary values for age and calorie intake are substituted, it is found that weight gain per kilocalorie ingested is less in the uremic groups.

\section{Discussion}

The mortality in the experimental rats was high, for it was difficult to control the amount of renal tissue removed so that a reproducible moderate uremia resulted. The technique involves ligaturing the upper and lower poles of one kidney. Addis [1] produced levels of serum in urea of $65 \mathrm{mg} / 100 \mathrm{ml}$ in 30-day old rats on a $23 \%$ protein diet by removing $75 \%$ of kidney mass. He removed one kidney and then, at the same operation, excised tissue from the upper and lower poles of the contralateral kidney. The tissue removed was weighed and an estimate of the quantity of func- tioning renal mass remaining was calculated. The mortality at 1 week after the operation was $13 \%$. This technique may provide easier control of the degree of uremia; however, whichever method is used, the operation takes less than $5 \mathrm{~min}$ to perform and therefore sufficient rats with a satisfactory degree of uremia can be obtained relatively easily.

In both males and females the effect of uremia on the increase in body weight is striking. Morrison [8] used a similar technique in a study of the effects of long standing renal insufficiency in the rat. No evidence of growth retardation was noted until 70 days of age, but the degree of renal insufficiency was less: i.e., BUN levels of $36.0 \mathrm{mg} / 100 \mathrm{ml} \pm 2.8 \mathrm{mg} / 100 \mathrm{ml}$ at 140 days. Animals killed at this time and later had adrenocortical and parathyroid hypertrophy and hyperplasia, pituitary and testicular atrophy, and cardiac enlargement. Bone changes were typical of renal osteodystrophy. Morrison also noted that animals which died

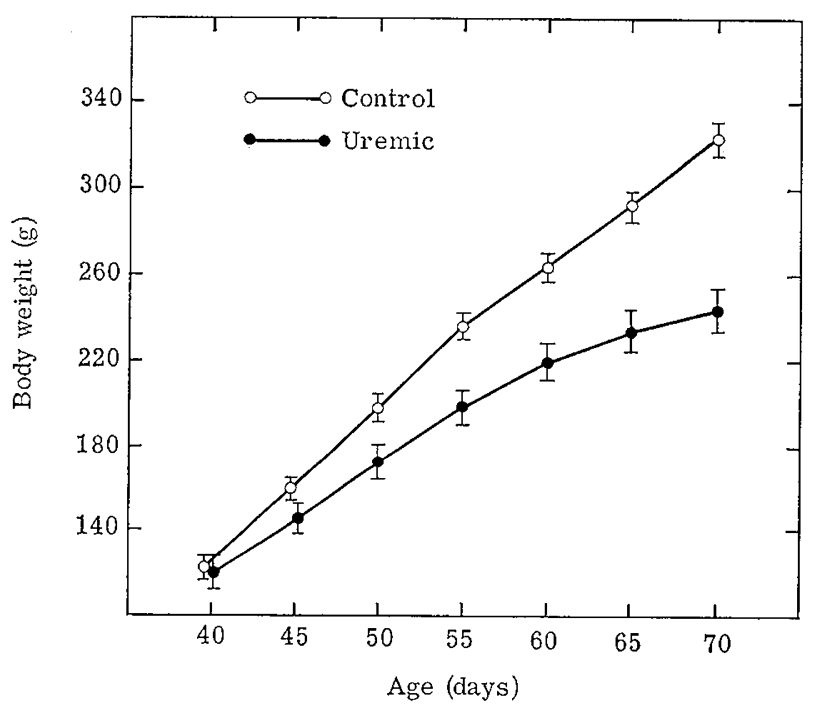

Fig. 2. Male rats: body weight plotted against age, showing the mean and SEM $\times 2$ at 5 -day intervals. 


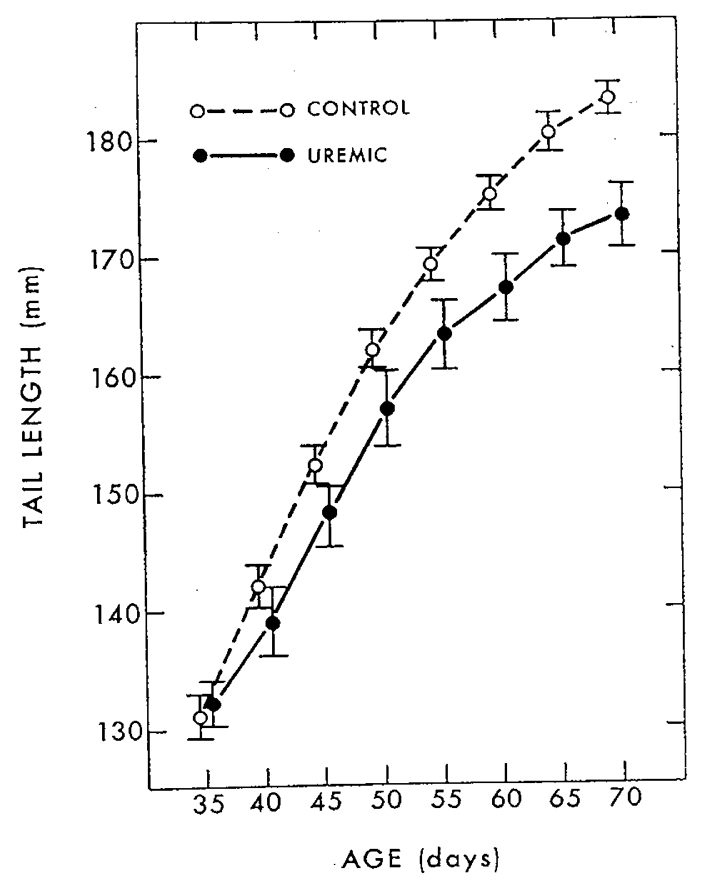

Fig. 3. Female rats: tail length plotted against age, showing the mean and SEM $\times 2$ at 5-day intervals.

suffered a sharp drop in weight during the week before death, when they became obviously ill. Our experience was similar and we therefore excluded from the study all rats who failed to survive to 80 days, i.e., 10 days after the period of observation. Thus, all our rats appeared to be healthy during the study and the changes noted in weight and tail length and calorie intake could not be attributed to the effects of terminal uremia.

The role of calorie deficit in the pathogenesis of the growth retardation of chronic renal disease is still uncertain. Although West and Smith [11] suggested that calorie deficiency was an important factor, their evidence was inconclusive and was not confirmed in a later study by Bergstrom et al. (2). Poor calorie intake in children on chronic hemodialysis has recently been documented and the level of calorie intake correlated reasonably well with growth [10]. Moreover, increased intake in these children, supplied by feeding a calorie supplement, was accompanied by an increase in growth rate. Further support for the view that calorie malnutrition occurs in uremic patients has been presented in a study of changes in body composition in chronic renal failure [4].

The uremic rats in this study consumed an average of $15 \%$ fewer calories than control rats of the same weight (Table I). It is not possible to determine from

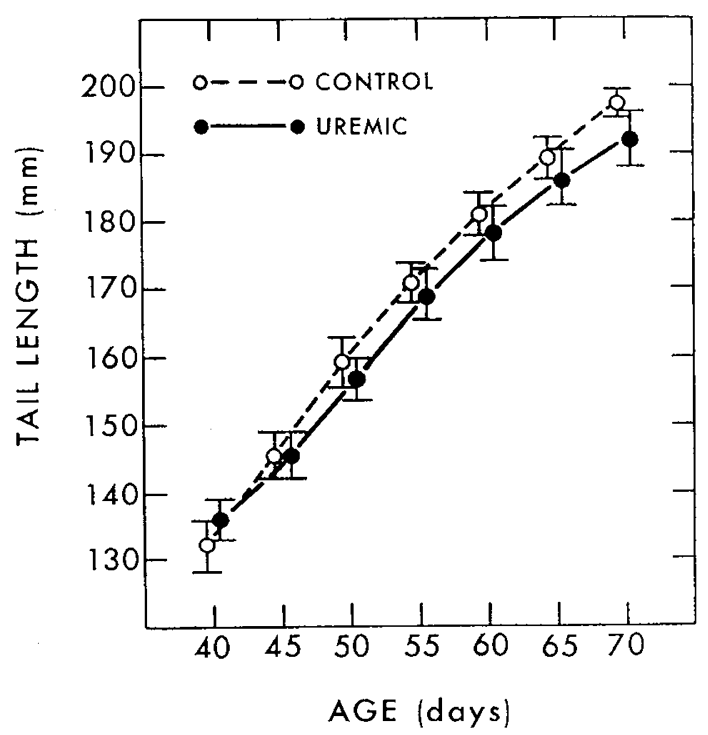

Fig. 4. Male rats: tail length plotted against age, showing the mean and SEM $\times 2$ at 5-day intervals.

Table II. Comparison between the calorie intakes of uremic and control rats at different weights

\begin{tabular}{|c|c|c|c|c|c|}
\hline \multicolumn{3}{|c|}{ Females } & \multicolumn{3}{|c|}{ Males } \\
\hline \multirow{2}{*}{ Body wt range, $g$} & \multicolumn{2}{|c|}{ Calorie intake, $\mathrm{kcal} / 24 \mathrm{hr}$} & \multirow{2}{*}{ Body wt range, $g$} & \multicolumn{2}{|c|}{ Calorie intake, $\mathrm{kcal} / 24 \mathrm{hr}$} \\
\hline & Uremic $^{1}$ & Control $^{1}$ & & Uremic $^{1}$ & Control $^{1}$ \\
\hline $100-119$ & $45.4 \pm 4.9$ & $46.7 \pm 0.9$ & $100-129$ & $52.0 \pm 6.4$ & $62.5 \pm 11.0^{2}$ \\
\hline $120-139$ & $48.7 \pm 6.3$ & $54.3 \pm 4.7^{2}$ & $130-159$ & $62.0 \pm 5.6$ & $70.8 \pm 8.4^{2}$ \\
\hline $140-159$ & $46.8 \pm 6.7$ & $56.7 \pm 6.0^{2}$ & $160-189$ & $63.2 \pm 8.7$ & $77.0 \pm 6.5^{2}$ \\
\hline $160-179$ & $54.9 \pm 8.9$ & $61.0 \pm 8.9^{2}$ & $190-219$ & $65.4 \pm 7.9$ & $83.0 \pm 8.9^{2}$ \\
\hline \multirow[t]{3}{*}{$180-199$} & $49.5 \pm 9.0$ & $59.8 \pm 8.8^{2}$ & $220-249$ & $60.7 \pm 11.7$ & $87.0 \pm 11.2^{2}$ \\
\hline & & & $250-279$ & $62.8 \pm 11.4$ & $84.6 \pm 6.5^{2}$ \\
\hline & & & $280-309$ & $85.0^{3}$ & $88.7 \pm 9.7$ \\
\hline
\end{tabular}

${ }^{1}$ Mean \pm 1 SD.

${ }^{2}$ Differences between means significant at $5 \%$ level.

3 Two rats only. 
this study whether the lower calorie intake was the cause or the result of the poor growth in the uremic rats. However, the model can be used to test this and other possible factors in uremic growth retardation. Significant differences in body weight were apparent by 55 days of age in both male and female rats; by dividing rats with uremia at this stage into pairs and then supplementing the diet of one of the pair by forced feeding, it should be possible to examine the importance of calorie intake by observing growth over the period from 55 to 70 days.

The analysis of regression of weight gain as a dependent variable of age and calorie intake suggests that calories are less efficiently utilized for growth in the uremic group. If calories ingested are only available for growth after the energy requirements for the maintenance of bodily functions have been satisfied, then the smaller food intakes of the rats with uremia will mean that a proportionately smaller amount of total calorie intake is available for growth in the uremic rats than in the controls. Thus, the calorie cost of growth will appear to be higher, even if it is not, and the differences in the regression analysis can be explained without proposing either an increased calorie requirement for maintenance of bodily functions or a less efficient utilization of calories for growth in the uremic rats. The suggestion that uremia may lead to increased energy requirements needs to be studied by paired feeding experiments, for, if substantiated, it might mean that the estimated calorie requirements of the child with uremia are greater than realized. Paired feeding studies on acidotic rats [5] have demonstrated considerably increased energy requirements, and this would be one factor to be investigated in further experiments using this model.

It is hoped that the model developed in the present experiments will prove useful in investigating the various factors such as hypertension, acidosis, osteodystrophy, hormonal alterations, protein calorie malnutrition, etc. [3] which have been implicated in the growth failure of uremia.

\section{Summary}

A rat model for the study of the pathogenesis of growth retardation in chronic renal failure is described. Growth in body weight and tail length was significantly less in rats with uremia compared with control subjects between 40 and 70 days of age. Food consumption was lower in rats with uremia compared with control rats of a similar body weight.

\section{References and Notes}

1. AdDIs, T.: Glomerular Nephritis Diagnosis and Treatment, pp. 61 and 274 (Macmillan Co., New York, 1948).

2. Bergstrom, W. H., Leon, A. S., and van Gemund, J. J.: Growth aberrations in renal disease. Ped. Clin. N. Amer., 11: 563 (1964).

3. Chantler, C., AND Holdyday, M. A.: Growth in children with renal disease with particular reference to the effects of calorie malnutrition: A review. Clin. Nephrol. (in press).

4. Coles, G. A.: Body composition in chronic renal failure. Quart. J. Med., 41: 25 (1972)

5. Cooke, R. E., Boyden, D. G., ANd Haller, E.: The relationship of acidosis and growth retardation. J. Pediat., 57: 326 (1960).

6. De Groot, D. A.: Tail growth in the thyroxine treated hypophysectomized rat as a sensitive criterion for growth hormone activity. Acta Endocrinol., 42: 423 (1963).

7. JONES, J. H., AND FosTer, C.: A salt mixture for use with basal diets either low or high in phosphorus. J. Nutr., 24: 245 (1942).

8. Morrison, A. B.: Experimentally induced chronic renal insufficiency in the rat. Lab. Invest., 11: 321 (1962).

9. Platr, R., Roscoe, M. H., and Smith, F. W.: Experimental renal failure. Clin. Sci., 11: 217 (1952).

10. Simmons, J. M., Wilson, C. J., Potrer, D. E., and Holliday, M. A.: Relation of calorie deficiency to growth failure in children on hemodialysis and the growth response to calorie supplementation. New Engl. J. Med., 285: 653 (1971).

11. West, C. D., AND SMith, W. C.: An attempt to elucidate the cause of growth retardation in renal disease. Amer. Med. Ass. Dis. Child., 91: 460 (1956).

12. Vitamin diet fortification mixture, Nutritional Biochemicals Corporation, Cleveland, Ohio.

13. Computer analysis (IBM $360 / 65$ at University College, London) using program O2R of the B.M.D. computer programs, W. J. Dixon, University of California, Berkeley, Los Angeles, London, 1970.

14. The authors acknowledge with gratitude the technical assistance of Mr. M. Buzon, and secretarial help from Ms. M. Tellschow and Ms. J. Kunitsugu. They are especially grateful to Dr. M. E. Abrams for statistical help.

15. Dr. C. Chantler is a UK Medical Research Council Traveling Fellow. Present address: Guy's Hospital, London Bridge, SE1 9RT, London, England.

16. The present address of Dr. E. Lieberman is: Childrens Hospital of Los Angeles, P.O. Box 54700, Los Angeles, Calif. 90054 (USA).

17. This research was supported by Public Health Service Research Grant No. AM 13306 from the National Institute of Arthritis and Metabolic Diseases.

18. Requests for reprints should be addressed to: C. Chantler, M.A., M.D., M.R.C.P., Department of Paediatrics, Guy's Hospital, London SEI 9RT, England.

19. Accepted for publication October $1,1973$. 